American Journal of Applied Sciences 7 (12): 1539-1549, 2010

ISSN 1546-9239

(C) 2010 Science Publications

\title{
A Laboratory Study of Curiosity Behavior in Feedback-Based Decisions
}

\author{
Takemi Fujikawa \\ Graduate School of Business, \\ University Sains Malaysia, Penang 11800, Malaysia
}

\begin{abstract}
Problem statement: This study adopts an interdisciplinary approach in conducting the study on "curiosity" with a toolset of experimental economics. Approach: I hypothesized that the Decision Makers (DMs) tended to exhibit curiosity behavior when two conditions were met: (1) The DMs faced "small feedback-based" decision problems; (2) The DMs bore tangible costs of their curiosity behavior. Results: This study was the first to address the phenomenon of curiosity, using an economics experiment, where the DMs received financial performance-based incentives (i.e., monetary payoffs that were contingent on their performance in the experiment). Economics studies the cost and benefit of any action made by the DMs, whereas psychologists do not. A key feature of the current experiment was that the DMs faced 100-fold binary choice between two alternatives, both of which yielded fixed payoffs. Conclusion/Recommendations: Experimental results were interpreted as a confirmation of the hypothesis that curiosity was aroused when the aforementioned two conditions were met.
\end{abstract}

Key words: Decision Making, small feedback-based decisions, curiosity, ambiguous treatment, hypothesis, hypothetical situations, frequent smoking, ambiguous/imperfect information

\section{INTRODUCTION}

This study is the first to study the psychological facet of curiosity behavior in "small feedback-based" decision problems with a toolset of experimental economics. Among remarkable methodological distinctions between experimental practice in economics and that in psychology, one remarkable distinction is that economists pay the participants (i.e., provide financial incentives) according to their decisions and performance, whereas psychologists do not. Thus, the participants in economics experiments bear tangible costs of their behavior in laboratories. A feature of the current experiment on curiosity is that the participants receive monetary payoffs that are contingent on their choice and performance. We shall show that the DMs exhibit curiosity-seeking behavior when they bear tangible monetary costs of their choice and behavior. Note that previous findings in experimental psychology are based on the absence of tangible monetary incentives to the participants.

A typical small feedback-based decision problem is characterized by three critical features (Barron and Erev, 2003; Fujikawa, 2007). First, the DMs face repeated tasks and make decisions, relying on the immediate feedback obtained in similar situations in the past. Second, each single choice is of little consequence in terms of net payoffs. Third, the DMs take little efforts and time in making decisions (Fujikawa, 2005; Fujikawa and Oda, 2005). The importance of shedding light on small feedback-based decision problems in investigating curiosity behavior is particularly concerned with curiosity about problematical behavior among adolescents, such as their frequent smoking. National Institutes of Health (1976) medically and legally defined age.

Nowadays people, especially adolescents, commit a crime or do delinquent behavior that is resulted from their curiosity. As an example, this study shall introduce problems of adolescent smoking, one of the main reasons of which is curiosity. All crime is economically costly: Smoking is a crime (Stockman, 2006). Smoking frequently or every day is prevalent among adolescents, some of whom smoke even in the school premises. They make a decision to smoke either frequently or every day, regardless of their understanding of dangers of smoking. We would observe some adolescents who had never smoked: Their exposure to tobacco ads, many of which appeal to young people, easily promotes curiosity about smoking. Having exhibited curiosity, they start and continue smoking and become regular smokers. They smoke with a consideration that smoking is fun, a passport to 
an exciting lifestyle (Lucas and Lloyd, 1999) and a little decision for their pleasure. Hence, it is a small decision for them to decide whether or not to smoke. In fact, Lucas and Lloyd (1999) present a questionnaire-based study with English secondary school students and the respondents state in the questionnaire that "Smoking just one cigarette would not hurt and smoking was pleasant once you got used to it." The adolescents make their decision either frequently or every day with spending little time and efforts, despite possible risk from smoking (e.g., risk of lung cancer). They start and continue smoking without careful consideration of the harmful effects of smoking. It is found that nearly half of the children in the U.S.A. tried cigarettes because their family members smoked (Greenlund et al., 1997). This finding implies that the adolescents initiated smoking without thinking of the possible risk of smoking, rather initiated smoking simply because their family members smoke. The adolescents see family members, especially parents, as a model. Most adolescents value their parents' behavior and opinions. Thus, they consider that, without thinking carefully, there is no problem to do the same as what their parents/family members do.

Many pupils smoke in school premises, knowing that smoking is a violation of school rules. They know that there is no "monetary" punishment available to them, even if they are found to be smoking. That pupils smoke in any part of school premises constitutes a violation of school rules. Usually, pupils who violate the rules will receive a disciplinary action. Each time they are found to have committed an offence against the rules, they will proceed through steps, the examples of which include, inter alia:

- Detention

- Recess

- Suspension from the school for a particular period

- Expulsion

However, none of the above steps relates to directly costly monetary punishments/sanctions. Although pupils are commonly informed and aware of the rules, some pupils make a decision-even everydayto smoke in the school premises, without taking into full consideration tangible monetary costs of their behavior.

A question now arises: Do pupils still wish to make a decision to smoke in the school premises if they bear tangible monetary costs of their behavior (i.e., wrongdoing)? In an attempt to answer this question, I conducted an economics experiment on curiosity in which the participants were asked to make their decisions and provided with monetary payoffs that was contingent on their decisions and performance.

Here is the supposition that curiosity refers to the presence of the DMs' "second-guessing" whereas intuition refers to the presence of only their "firstguessing". The adolescent is said to spend little time and efforts in making her decision (i.e., to start smoking). She, among many adolescents, has an intuition about smoking: the intuition that smoking is a health hazard-and hence her first-guessing about smoking. In fact, $90 \%$ of adolescents are aware that smoking is a health hazard, but few believes that smoking is a threat to their own health (Tuakli et al., 1990). In addition to her first-guessing, she also has her second-guessing about smoking that leads to curiosity about smoking. On the one hand, if she invokes only the first-guessing about smoking (e.g., possible risk from smoking), then she does not start smoking. On the other, if she invokes the second-guessing about smoking, then she exhibits curiosity that promotes her start smoking. We shall experimentally show that the DMs' second-guessing invokes the curiosity-seeking behavior.

This study attempts to investigate curiosity with an economics experiment that includes feedback-based decision problems. Repeated trials with an immediate, accurate feedback afford the DMs the opportunity to learn what their own choices bring to them in a specific situation. A practical example of how people especially, adolescents - act out their curiosity is addressed to initiation of smoking, as discussed above. In spite of laws and regulations against adolescents' smoking, they still try to find a way to get cigarettes. Either frequently or every day, they make a decision to smoke. After each smoking they receive an immediate feedback from it. For instance, they receive physical reactions immediately after each smoking, that is, they get high and/or feel relieved and relaxed. This can be evidenced by the statement (A National Legal-Action Antismoking Organization USA, 2008): "One of the reasons for adolescent attraction to smoking is curiosity about the physical reactions of it." Thus, adolescents' frequent smoking is to be discussed in the context of the repeated feedback-based decisions.

To achieve a tractable experiment environment as to curiosity behavior, for instance, let us consider a situation where the DMs are repeatedly asked to choose one of two urns from which they draw one ball. They are informed that Urn A contains only red balls and Urn B only black balls. The DMs are told, in advance, that they can receive $\$ 4$ if a red ball is drawn; $\$ 3$ if a black ball is drawn. With an immediate feedback after each choice, the DMs can gain an experience and outcome of 
their choices. If the DMs are asked to choose one of the urns for 100 times, how do they behave? Do they choose only Urn A during given 100 rounds, exhibiting their first-guessing about the information provided by the experimenter and hence intuition? Or, do they choose both urns, exhibiting their second-guessing and hence "curiosity"? Central to this question is the supposition that some perhaps wish to choose Urn B for certain times to check whether the information on the two urns given by the experimenter is true or false.

To answer these questions, this study implements a laboratory experiment that involves an ambiguous treatment, where the DMs receive ambiguous/imperfect information on the payoff distribution. The use of an ambiguous treatment can induce the DMs' secondguessing; that is, they are induced to invoke the secondguessing in the ambiguous situation. Ambiguity refers to the absence of a single coherent interpretation of a situation or, obversely, the presence of more than one plausible interpretation (Loewenstein, 1994). Several authors (Einhorn and Hogarth, 1986; Fujikawa, 2007; Mukerji, 1998) define ambiguity as an intermediate state between "uncertainty" (i.e., the DMs receive no information to rule out any probability distribution possibilities) and "risk" (i.e., they receive one defined probability distribution). In the current experiment, there are two states of nature: a favorable state and an unfavorable state, but only one of them obtains on any given round during the experiment. That is, one state is a real state that is being realized in the experiment, whereas another is a dummy state. The participants are not disclosed which of the two states are realized across the experiment (If one defines "deception" as the use of intentional and explicit provision of erroneous information as in Hertwig and Ortmann (2008), then providing the participants with the ambiguous information constitutes nondeceptive design). The inclusion of the dummy information on the payoff distribution provides an ambiguity treatment in which the DMs exhibit the second-guessing that induces their curiosity behavior.

The current experiment is done in the context of developing the following questions:

- Do the DMs exhibit curiosity when they face "small feedback-based" decision problems? In other words, do the DMs exhibit curiosity when they face repeated-play decision tasks with an immediate, accurate feedback?

- Do the DMs exhibit curiosity when there is ambiguous/imperfect information on the decision tasks available? In other words, do the DMs exhibit curiosity in the absence of perfect information on the payoff distribution? The answer to this question would turn out on close examination of the previous finding (Reio and Petrosko, 2006) that a lack of information arouses curiosity.

- Do the DMs exhibit curiosity when they bear direct monetary costs of curiosity behavior?

Experimental psychology in curiosity: Our natural "curiosity" is a major impetus behind scientific discovery and the advancement of civilization (Berlyne, 1978; Bjorno, 2003; Dewey, 1909; Elmikaty, 2005; Loewy, 1998). Previous authors have documented the importance of curiosity. Bruner (1966) documents the importance of curiosity by saying that curiosity is so important that it is essential to the survival not only of the individual but of the species. As pointed out by Reio and Petrosko (2006) curiosity is linked to a wide range of key developmentally relevant tasks, ranging from the play and school activities of children to the study (Berlyne, 1960) and leisure activities of adults (Reio, 2003; Reio and Wiswell, 2000).

Despite different definitions of curiosity employed by different authors, an aspect of curiosity is concerned with information seeking toward uncertainty. Cicero (1914) refers to curiosity as a "passion for learning" and an "innate love of learning and of knowledge" while Hunt (1963) as a "motivation inherent in information processing". Specific curiosity is described as the desire for a particular piece of information (Loewenstein, 1994). Piaget (1950) views curiosity as the product of cognitive disequilibrium evoked by the DM's attempt to assimilate new information into existing cognitive structures. On their nature to be curious, individuals are motivated to discover new ways to solve salient problems to adapt successfully and continually (Reio and Petrosko, 2006). More importantly, Dewey (1909) states that curiosity is a vital component of thinking and it is the only sure guarantee of the acquisition of the primary facts on which inference must base itself. Curiosity is an internal state occasioned when subjective uncertainty generates a tendency to engage in exploratory behavior aimed at resolving or partially mitigating the uncertainty (Berlyne, 1978).

A number of experiments on curiosity were conducted and reported by psychologists (Berlyne, 1954; Litman and Spielberger, 2003; Lowry and Johnson, 1981; Reio and Petrosko, 2006). The authors implemented psychology experiments to define curiosity in decision making in which the DMs were asked to make decisions in hypothetical situations, such as interviews and questionnaires. The existence of curiosity and identified curiosity factors was examined 
by conducting questionnaires with undergraduates (Litman and Spielberger, 2003). Ainley (1987) empirically examined the existence of cognitive types of curiosity. Reio and Petrosko (2006) conducted questionnaires-based experiments to check an appropriateness of a series of hypotheses on curiosity presented by previous authors (Giambra et al., 1992; Olson and Camp, 1984; Spielberger and Starr, 1994). The results of previous questionnaires revealed the existence of information-seeking curiosity. It must be noted here that the authors presented individual DMs' behavior, resulting from the total absence of monetary rewards.

Experimental practice in economics: Despite elegant previous psychological studies, there has been so far no experimental economics literature on curiosity in spite of my conjecture that experimental economics and corresponding areas in psychology (i.e., experimental psychology and behavioral decision making) are somewhat closely related fields that apply decision theory and scientific research on human decision making. The conjecture follows that both fields (i.e., experimental economics and experimental psychology) should implement a reasonable experimental design. This motivates and drives me to do the current research on curiosity with a toolset of experimental economics. The motivation is supported by a main importance of applying a method of experimental economics in analysing human behavior that is summarised as the following two remarks. One remark is that - due to the nature of psychology experiments that is different than an approach of experimental economics - all of the psychologists introduced above conducted psychology experiments on curiosity with hypothetical situations, such as questionnaires and interviews. That is, none of the authors conducted the experiments in which the DMs received monetary payoffs, contingent on their performance in the experiments. Not only the authors but mainstream psychologists are more casual about defining their participants' incentives in experimental tasks (This is not to say that all psychologists have used unpaid participants. There exist some psychology experiments in which the DMs received monetary payoff according to their performance (Shafir and Tversky, 1992)). In fact, most psychologists feel no necessity to offer salient rewards: The admonition to the participants to "do their best" is acceptable (Friedman and Sunder, 1994). It is highlighted that the psychologists did not take into consideration an analysis of (monetary) costs and benefits of their experimental subjects' action in the experiments.
However, a large caveat must be issued here: Economists study costs and benefits of any action made by the DMs. As such, extrinsic rewards are one of the most important determinants of decision making among experimental economists. It is inevitable to provide experimental subjects with the financial rewards, which are contingent on their performance in the experiments (Fujikawa, 2006). Monetary incentives are commonly absent in the research of psychologists: This makes their study vulnerable to the criticism that the results are not meaningful (Smith, 1991). Money is a compelling incentive, in that most people will study for it (Knutson and Peterson, 2005). Employing financial rewards is considered as one of experimental standards in economics (Hertwig and Ortmann, 2001). The use of questionnaires can be problematic because the DMs have no incentives to report their strategy reliably (Sonnemans, 1998; Ciccone and Costain, 2004). Some (Offerman et al., 1996) argue that the DMs are not provided with an incentive to carry out the estimation task seriously in some non-economic experiments (Dawes et al., 1986; Rapoport, 1988; Suleiman and Rapoport, 1992). This argument is supported by some empirical evidence (Jamal and Sunder, 1991; Smith and Walker, 1993) that the addition of rewards makes the results of experiments more reliable and reproducible. For example, in a post-experiment questionnaire (Offerman et al., 1996), 50\% of the DMs stated that they would have answered differently if no incentives had been provided. What the DMs say they would do in hypothetical situations does not necessarily correspond to what they actually do (Friedman and Cassar, 2004a; Fujikawa, 2007). The present study avoids this shortcoming and differs by providing the DMs with clear, monetary incentives for revealing true beliefs. Although, there is an assertion maintained by psychologists (Thaler et al., 1997) that running experiments with hypothetical questions is inexpensive, fast and convenient, I did not obey the assertion in implementing the current experiment on curiosity.

Another remark that strikes us is concerned with "deception" in psychology experiments; whereas experimental economists may not deceive experimental subjects. A large fraction of social psychology experiments attempt to mislead the DMs as to the true nature of the experimental tasks (Friedman and Cassar, 2004b; Hertwig and Ortmann, 2001; Bohnet and Zeckhauser, 2004). Psychologists sometimes create experimental treatments by deceiving subjects (Camerer and Thaler, 1995). However, deception of any kind is taboo among experimental economists. In fact, there is very strong norm in experimental economics: 
An economic journal will not publish an experiment in which deception is used; whereas deception is commonplace and accepted in psychology journals (Croson, 2005). That is, the ethic in experimental economics prohibits the deception of experimental subjects. With a guarantee of no deception, the DMs make choices without trying to "game" the experimenter by figuring out what they are "really" looking for (Zak, 2004). A convincing body of Engelmann and Strobel (2000) documents that - in many of the social psychological experiments in which the information about other people's decisions is provided - this information is rigged and the DMs are clearly deceived in previous studies (Alicke and Largo, 1995; Sherman et al., 1984). Engelmann and Strobel (2000) follow that it is quite obvious that, in some studies (Alicke and Largo, 1995; Krueger and Clement, 1994), the DMs might have become suspicious about this information and thus might have discarded it. In the present study, the DMs are not deceived.

\section{MATERIALS AND METHODS}

Computerized experiment: Until the mid1970s, all experiments on individual decision making were run manually by economists and psychologists, that is, the experiments were hand run. Yet, the current experiment is computerized in the light of advantages of computerized experiments. One advantage is that computers speed up the execution and allow more periods performed by the participants. Since the current experiment includes an iterated game of 100 rounds, the computerized experiment can regain this advantage. Once software is properly installed, it minimizes marginal cost in terms of experimenters' time and cost per observation (Friedman and Cassar, 2004a).

Apparatus and procedure: The current experiment was conducted at Kyoto Experimental Economics Laboratory (KEEL), Japan, with 31 participants, who were undergraduates at Kyoto Sangyo University and recruited with the recruitment system at KEEL. On arrival at KEEL, each participant was assigned a workstation that displayed an experimental screen. The participants received verbal and written instruction and were given an opportunity to ask questions individually before the experiment. The instruction included explanations of computer screens and experimental procedure for consolidation of the experiment. The instruction was read aloud and the participants were given an opportunity to ask questions individually. At the conclusion of the experiment, they were paid individually and privately at a conversion rate of one point to 0.6 Yen (about 0.5 US cent at the time of the experiment) and received no initial (showing up) fee.

They were asked to perform the following choice problem:

State A: Choose between L: $(6,1)$ and R: $(5,1)$ State B: Choose between L: $(4,1)$ and R: $(3,1)$

Note that we let $(\mathrm{V}, 1)$ be an alternative that yields a sure payoff of $\mathrm{V}$ points: one selection of this alternative enables the participants to earn $\mathrm{V}$ points for sure. They were seated in front of a computer screen that presented two marked keys: one was marked $\mathrm{L}$ and another R. They were told that the experiment included 100 rounds and their task was to select one of the two keys in each round $t(t=1,2, \ldots, 100)$. The computer provided the participants with binary types of feedback immediately following each choice: (1) the payoff for the choice that appeared on the screen for the duration of one second and (2) an update of an accumulating payoff counter, which was constantly displayed.

The experiment was conducted under the condition that the participants were, at the beginning of the experiment, presented with two equally likely states of the world: State A (a priori relatively high state) and State B (a priori relatively low state). Unannounced to the participants, State A was a dummy state and State B was an actual state. That is, they were not disclosed which of the two states of the world was realized in the experiment, but disclosed that they were asked to choose either $\mathrm{L}$ or $\mathrm{R}$ on the computer screen for 100 times. However, they were, in advance, disclosed that an actual state of the world had been predetermined (before they started experimental tasks) and the same state of the world was realized across the experiment. Thus, the participants were informed of the payoff structure of the experiment, except for the realization of the state of the world.

\section{RESULTS}

The results revealed that the participants chose both $\mathrm{L}$ and $\mathrm{R}$ within given 100 rounds. The aggregated proportion of $\mathrm{L}$ choices was 0.94 . The results showed that $\mathrm{L}$ was chosen, on average, 94 out of 100 times. Figure 1 presents the proportion of $\mathrm{L}$ choices in blocks of ten rounds over 31 participants. Observation of the results of individual participants showed that, of 31 participants:

Observation 1: About 9 participants (29\%) chose only L during the experiment

Observation 2: About 1 participant chose only $\mathrm{L}$ in rounds 1-90; only $\mathrm{R}$ in rounds $91-100$

Observation 3: About 19 participants (61\%) chose both $\mathrm{L}$ and $\mathrm{R}$ in rounds $1-10$; only $\mathrm{L}$ in rounds 11-100 
Am. J. Applied Sci., 7 (12): 1539-1549, 2010

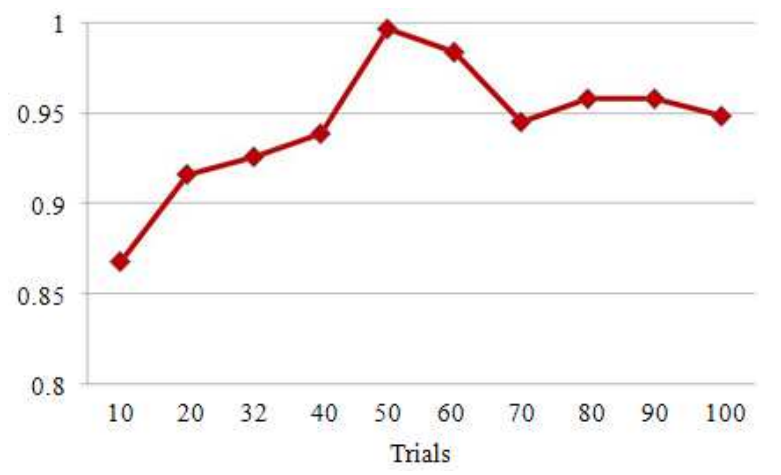

Fig. 1: The aggregated proportion of $\mathrm{L}$ choices in blocks of ten rounds

Observation 4: About 1 participant chose only $\mathrm{L}$ in rounds 1-50; both $\mathrm{L}$ and $\mathrm{R}$ in rounds 51-60; only $\mathrm{L}$ in rounds $61-100$

Observation 5: About 1 participant chose only $\mathrm{L}$ in rounds 1-50; both $\mathrm{L}$ and $\mathrm{R}$ in rounds 51- 60; only $\mathrm{R}$ in rounds $61-100$

Given that the orthodox conception defines economic rationality as the maximization of utility function defined on a sure amount of money, the results revealed that the participants exhibited a string of irrational economic behaviors. Whether or not the principle of economic rational choice constitutes the "gold" standard for an analysis of decision making, it seems idealized decisions for the participants to always choose L during given 100 rounds, no matter which of the two states they believe is realized. However, the results reveal that some participants chose both $\mathrm{L}$ and $\mathrm{R}$ within 100 rounds (i.e., they mixed between the two alternatives), exhibiting curiosity-seeking behavior. Having observed the participants' curiosity-seeking behavior, below are illustrated behavioral interpretations of the curiosity-seeking behavior.

\section{DISCUSSION}

Curiosity-seeking due to suspiciousness: We raise a discussion on curiosity-seeking behavior that is invoked by the DMs' "suspiciousness" about the information provided by others. We shall show that the participants of the experiment exhibited curiosity-seeking behavior as a result of their suspicions towards the information provided by the experimenter. It appears that a subset of the participants exhibited the curiosity-seeking behavior in the first ten rounds of the experiment. The results (Observation 3) show that $61 \%$ of the participants chose both $\mathrm{L}$ and $\mathrm{R}$ in the first ten rounds of the experiment. Note that $\mathrm{L}$ dominates $\mathrm{R}$ no matter which of the two states (State A and State B) was being realized during the experiment. One implies that the participants' choice of both alternatives during the first ten rounds was made in order for them to check whether or not the given information on the payoff structure was true. As shown above, a current experimental design allowed the participants to observe and check the immediate feedback from their choice at each round. There exists the effect of suspiciousness on the information provided by experimenters. Due to suspiciousness, the participants exhibited curiosity that led them to try both an attractive/preferable alternative (L) and an unattractive alternative $(\mathrm{R})$ so as to check the outcome of the alternatives with an immediate feedback after each choice. If, on the other hand, the participants were unsuspicious, then they were not interested in the unattractive alternative at all and hence were willing to choose only $\mathrm{L}$ for all rounds of the experiment in order to maximize their payoffs.

What is the possible cause of the DMs' suspiciousness? It is viewed as the DMs' "secondguessing" towards the information available to them. The first-guessing is concerned with the DMs' intuition about the information: the intuition that $\mathrm{L}$ yields higher payoffs than $\mathrm{R}$, no matter which state of the world is realized. The second-guessing is concerned with the DMs' suspiciousness about the information: They guess that R may perhaps yield higher payoffs than L, despite the information provided by the experimenter. Given the information provided, the participants can retain the first-guessing about the payoff structure and hence the intuition. If they only have the first-guess, then they are not interested in choosing $\mathrm{R}$, but in choosing only $\mathrm{L}$ during the experiment. That is, they do not exhibit curiosity. On the other hand, having retained the firstguessing, some participants retain the second-guessing too. They become interested in choosing $\mathrm{R}$ for certain times to observe what $\mathrm{R}$ can yield so as to feel certain that $\mathrm{L}$ yields higher payoffs than $\mathrm{R}$, as the DMs are told so by the experimenter. The DMs' second-guessing invokes their curiosity-seeking behavior to try both an attractive alternative and an unattractive alternative.

Suspicion was invoked by those participants who knowingly participated in the manipulative (ambiguity) experiment and attempted to resist the manipulative information. The current experiment used manipulation of the information on the payoff structure. The manipulation was used to create an ambiguity treatment so as to induce the participants' second-guess. The effect of suspiciousness should not be negligible. There should be a major behavioral difference between the findings from the experimental data of the suspicious participants and the findings from the data of the 
unsuspicious/naive participants. The behavioral difference is concerned with the participants' curiosityseeking behavior.

There raises a concern about the effect of suspiciousness for discussion on the adolescent problem behavior that is evoked as a result of a consequence of adolescent curiosity. One major adolescent problem behavior is initiation of smoking. Adolescent smoking has still been a problem, despite the launch of a number of health education programmes on smoking. In addition, there are also a number of antismoking campaigns with an aim of reducing adolescent smoking. These campaigns make an announcement of the harmful effects of smoking, such as "Smoking increases the risk of lung cancer." Regardless of the campaigns, many adolescents do not fully trust but are optimistic about the potential risk of smoking reported through the campaigns. The adolescents' distrust may cause suspiciousness towards the information on dangers of smoking. Due to their suspiciousness, the adolescents exhibit rebelliousness that leads them to exhibit curiosity about smoking and they get initiated into smoking. Besides a series of health promotion programmes on smoking conducted at schools, we observe parent-adolescent discussions at each home, where parents introduce the possible harmful effects of smoking to the adolescents, regardless of whether they have engaged in delinquent behavior in the past. Parentadolescent discussions are good opportunity where the parents can discipline their children. Since the parents know that the adolescents today face many temptations that include not only initiation of smoking but drinking, the parents are willing to hold parent-adolescent discussions with mutual trust which is important in a parent-adolescent relationship. However, the adolescents do not all mature so that they express distrust/suspicions of the accuracy of the information provided by their parents.

Curiosity-seeking due to boredom: We present a perspective on the nature of "boredom" that is a sign of curiosity that tends to indicate inactive exploration towards the DMs' behavior. Here is a two-fold presumption that has much to contribute to our discussion: First, the DMs with an active exploration tend to actively participate in the decision tasks, aiming at maximizing their obtained payoffs (This study maintains two assumptions: The first is an assumption of "nonsatiation" in money that states the DMs are nonsatiated with money, that is, the more money gives them a higher level of utility. The second assumption is that many of us want more of monetary incentives and there is no satiation over the course of the experiment (Hunt, 1963). On the contrary, there exists satiation in non-salient incentives that are commonly employed by psychologists (e.g., grade points)). Second, the DMs with an inactive exploration tend not to actively participate in the decision tasks but to participate being reluctant to maximize their payoffs. The DMs exhibit curiosity to adventure and risky behavior as an antidote to boredom which results when life becomes routine and humdrum (Dowling and Yap, 2006).

The results (Observation 4) show that one participant chose only L during the first 50 rounds, both $\mathrm{L}$ and $\mathrm{R}$ during the middle of the experiment and only $\mathrm{L}$ for the rest of the round. Choosing only $L$ for the first 50 rounds is associated with her "unsuspiciousness" towards the information on the payoff structure given by the experimenter and hence, non-curiosity seeking behavior. Let us indulge the following supposition that, during the first 50 rounds, she was satiated with her choice (i.e., choosing only L) and its outcomes, though the experimental task became routine and humdrum. Having gone through decision-making processes for 50 times with her satisfaction, she was drawn by her curiosity that was invoked as a result of boredom and led her to try an unattractive alternative (R) for some times. After trying $\mathrm{R}$ then, she moved back to $\mathrm{L}$ and kept choosing only $\mathrm{L}$ until the end of the rounds, without exhibiting curiosity.

The notion of curiosity due to boredom is addressed to problems related to adolescent smoking. Boredom after participating everyday in routine and humdrum activities in the school would result in curiosity. There is an information that cigarette smoking may reduce and relieve boredom and fatigue and in some cases help adolescents to escape the harsh realities of their world (Madu and Matla, 2003). This sort of information has been disseminated among adolescents. Hence, many of them start and continue smoking with their expectation that smoking can reduce boredom. One asserts that active participation in school communication activities and sport activities develop students' interests, which can help to keep them away from boredom and away from smoking. The schools and law-enforcement agencies should take note of this assertion.

Curiosity-seeking due to the end effect: The DMs develop a pattern of behavior followed by the "end effect". The experimental results reveal the end effect towards the end of experimental tasks (i.e., in the last ten rounds). The end effect is a change in the participants' behavior as the time periods reach to the time to the end. In other words, the end effect is 
Am. J. Applied Sci., 7 (12): 1539-1549, 2010

characterized by a change in their behavior towards the last rounds of the experiment. An attempt to explain curiosity-seeking behavior as a result of the end effect is based on the idea of the incomplete/ambiguous information on the payoff structure. The results (Observation 3) show that one participant chose only $\mathrm{L}$ in rounds 1-90 without exhibiting curiosity and chose only $\mathrm{R}$ in rounds $91-100$ with exhibiting curiosity in order for her to observe what the unattractive alternative (R) could yield.

Curiosity due to the end effect concerns initiation of smoking behavior among school students. Smoking initiation is a major problem among a number of highschool students who have completed final stage of highschool and await a graduation ceremony. They are clearly informed of the date of the ceremony, so that they can know when they completely end their highschool life. It attracts an attention that even those students who have never smoked during high-school years are reported to start and continue smoking. For example, in Australia, there is "Schoolies" that refers to the Australian tradition of high-school graduates having week-long holidays following the end of their final exams in late November and early December (Wikipedia). Schoolies events include concerts, dances and parties in which many adolescents initiate smoking and drinking.

Decision making in the absence of tangible costs: One primary point of this study is to design an economics experiment on curiosity in which compensation (i.e., monetary payoffs) is applied to make choices meaningful. This is critical because there is a tangible cost associated with behaving irrationally in the present experiment; whilst there is no tangible cost in previous "questionnaire-based" experiments on curiosity run by psychologists. In other words, a cost of curiosity is incurred to the DMs in the current experiment, whereas it is not incurred in the previous psychology experiments. A convincing body of research demonstrates that the use of questionnaires can be problematic because the DMs have no incentives to report their strategy reliably (Sonnemans, 1998). The addition of monetary rewards makes the results of experiments more reliable and reproducible (Jamal and Sunder, 1991; Smith and Walker, 1993). Camerer and Hogarth (1999) present an analysis of the behavior of the experimental subjects who are paid zero, low or high financial performance-based incentives. Camerer and Hogarth demonstrate that higher incentives do often improve the subjects' performance. The current experiment is designed to test the hypothesis that the DMs exhibit curiosity even when a tangible cost of curiosity is incurred. This hypothesis is supported by the current results. It reveals that $\mathrm{L}$ was overall chosen 94 out of 100 times. It evidently suggests that the participants of the current experiment exhibited curiosity in making decisions.

Decision making in the absence of perfect information: Homo economics is a rational DM with perfect information and perfectly ordered preferences (Aktipis and Kurzban, 2004). Now, I hypothesise that the DMs without perfect information on the payoff structure would behave irrationally with exhibiting curiosity. The current experiment is designed to obtain data that support this hypothesis. The experiment uses a design of drawing offers from an ambiguous distribution. In other words, the experiment consists of an ambiguous treatment in which the perfect information on the payoff structure is not available to the participants. The results show that they exhibited curiosity by exploring (choosing) both alternatives within given 100 rounds. The results support the conjecture that curiosity is aroused even when the objective, perfect information on the payoff distribution is not available to the participants.

\section{CONCLUSION}

This study has presented the persistent nature of curiosity behavior with an economics experiment on sequential decision making problems. On the one hand, a number of previous psychology papers report questionnaire-based experiments on curiosity; that is, the authors have implemented the experiments with experimental psychology approaches. Even though there exist a number of previous experimental studies on curiosity conducted by psychologists, no economics experiments on curiosity have been conducted in which the participants receive monetary payoffs, contingent on their performance in the experiments. For example, Berlyne (1954) tested several elements of his theory by conducting experiments on curiosity involving human subjects. Yet, Loewenstein (1994) points out that the Berlyne's experiments are fabulously complicated. Berlyne's experimental apparatus and procedure are against the principle of experimental economics that should create the simplest possible economic environment in which we can address research issues (Friedman and Cassar, 2004b).

On the other hand, this study has presented the current experiment with salient rewards to the participants. The experiment is designed in the light of the sine qua non that a combination of experimental economics and experimental psychology approaches 
may succeed in providing a methodology for reconciling prescriptive and descriptive model of decision making. The current experimental study makes several contributions: This study examines curiosity behavior with an experiment with binary choice tasks, whereas previous literature has not employed binary choice tasks to examine curiosity behavior. My recent study (Fujikawa, 2009) draws up an outline for the binary choice tasks: There are many situations in which a binary restriction seems quite reasonable. A number of studies (Alessie et al., 2004; Moon, 2004) shed some lights on the complexity within a binary choice framework. Teraji (2003) adduce an example: Even when we talk about economic thought, we often think in terms of two alternative schools or approaches, such as Monetarist versus Keynesian, Historical versus Analytical and Rational versus Evolutionary.

To check hypotheses developed in this study, an economics experiment was conducted in which the participants received cash payoffs contingent on their performance. The experiment is the first systematic attempt to investigate an individual DMs' curiosity in the face of tangible costs of their curiosity. Experimental results support the hypotheses, revealing that curiosity is aroused even when the DMs are not disclosed the perfect information on the payoff structure. It is important to know from the current results that curiosity is aroused even when the DMs should incur tangible costs of curiosity. Yet, one asserts that much less curiosity would be observed in the situation where the DMs bear tangible costs of their curiosity behavior than in the situation where they do not need to bear behavioral costs.

I would like to conclude by stating that the number of adolescents who initiate smoking is a pointer to the fact that schools need to intensify preventive programmes and to introduce punitive monetary penalties. Introduction of the punitive monetary provisions can alter both adolescents' and parents' mindset about initiation of smoking. Since many of the illicit cigarette smokers indicate boredom, tiredness and stress, under which they use those substances, it is necessary to provide enough recreational facilities in schools (Madu and Matla, 2003). These would help in reducing the number of adolescents' smoking.

\section{REFERENCES}

A National Legal-Action Antismoking Organization USA, 2008. Action on smoking and health. http://www.ash.org.uk/
Ainley, M.D., 1987. The factor structure of curiosity measures: Breadth and depth of interest curiosity styles. Aust. J. Psychol., 39: 53-59. DOI: 10.1080/00049538708259035

Aktipis, C.A. and R. Kurzban, 2004. Is Homo Economicus Extinct: Vernon Smith, Daniel Kahneman and the Evolutionary Perspective. In: Advances in Austrian Economics, Koppl, R. (Ed.). Elsevier, Amsterdam, pp: 135-153.

Alessie, R., S. Hochguertel and A. van Soest, 2004. Ownership of stocks and mutual funds: A panel data analysis. Rev. Econ. Stat., 86: 783-796. http://ideas.repec.org/p/ner/tilbur/urnnbnnlui12140722.html

Alicke, M.D. and E. Largo, 1995. The role of the self in the false consensus effect. J. Exp. Soc. Psychol., 31: 28-47. DOI: 10.1006/JESP.1995.1002

Barron, G. and I. Erev, 2003. Small feedback-based decisions and their limited correspondence to description-based decisions. J. Behav. Decision Mak., 16: 215-233. DOI: 10.1002/bdm.443

Berlyne, D.E., 1954. An experimental study of human curiosity. British J. Psychol., 45: 256-265. http://www.ncbi.nlm.nih.gov/pubmed/13219284

Berlyne, D.E., 1960. Conflict, arousal and curiosity. 1st Edn., McGraw-Hill, New York. pp: 350.

Berlyne, D. E., 1978. Curiosity and learning. Motivat. Emot., 2: 97-175. DOI: 10.1007/BF00993037

Bjorno, L., 2003. Features of underwater acoustics from Aristotle to our time. Acoustical Phys., 49: 24-30. DOI: $10.1134 / 1.1537384$

Bohnet, I. and R. Zeckhauser, 2004. Trust, risk and betrayal. J. Econ. Behav. Org., 55: 467-484. DOI: 10.1016/j.jebo.2003.11.004

Bruner, J.S., 1966. Toward a Theory of Instruction. 1st Edn., Belknap Press, Cambridge, MA., pp: 176. ISBN: 0-674-89701-3

Camerer, C.F. and R.M. Hogarth, 1999. The effects of financial incentives in experiments: A review and capital-labor-production framework. J. Risk Uncertainty, $\quad$ 19: 7-42. DOI: 10.1023/A:1007850605129

Camerer, C.F. and R.H. Thaler, 1995. Anomalies: Ultimatums, dictators and manners. J. Econ. Perspectives, 9: 209-219. http://www.jstor.org/pss/2138174

Ciccone, A. and J. Costain, 2004. On payoff heterogeneity in games with strategic complementarities. Oxford Econ. Papers, 56: 701-713. http://www.crei.cat/research/wpapers/on\%20payoff\%2 Ociccone.pdf

Cicero, 1914. De Finibus bonorum et malorum. http://www.apassion4jazz.net/juke.html 
Croson, R., 2005. The method of experimental economics. Int. Negotiation, 10: 131-148. http://cbees.utdallas.edu/ crosonr/research/\%5B27 $\% 5 \mathrm{D} . \mathrm{pdf}$

Dawes, R.M., J.M. Orbell, R.T. Simmons and van de A.J.C. Kragt, 1986. Organizing groups for collective action. Am. Polit. Sci. Rev., 80: 1171-1184. http://www.citeulike.org/user/rburnett/article/876378

Dewey, J., 1909. How We Think. 1st Edn., D.C. Heath, Lexington, MA., pp: 224.

Dowling, J.M. and C.F. Yap, 2006. Homeostasis and Well Being. http://ideas.repec.org/p/siu/wpaper/092006.html

Einhorn, H.J. and R.M. Hogarth, 1986. Decision making under ambiguity. J. Bus., 59: 225-250. http://ideas.repec.org/a/ucp/jnlbus/v59y1986i4ps22 5-50.html

Elmikaty, H.S., 2005. Science education: On the agenda of the library of Alexandria. Museum Int., 57: 92-99. DOI: 10.1111/j.1468-0033.2005.00517.x

Engelmann, D. and M. Strobel, 2000. The false consensus effect disappears if representative information and monetary incentives are given. Exp. Econ., 3: 241-260. http://ideas.repec.org/a/kap/expeco/v3y2000i3p241 $-260 . \mathrm{html}$

Friedman, D. and A. Cassar, 2004a. Do it: Running a Laboratory Session. In: Economics Lab, Friedman, D. and A. Cassar (Eds.). Routledge, London, pp: 65-74.

Friedman, D. and A. Cassar, 2004b. First Principles: Induced Value Theory. In: Economics Lab, Friedman D. and A. Cassar (Eds.). Routledge, London, pp: 25-31.

Friedman, D. and S. Sunder, 1994. Experimental Methods: A Primer for Economists. 1st Edn., Cambridge University Press, New York, pp: 229. ISBN: 0-521-45068-3

Fujikawa, T., 2006. Experimental economics and small decision-making problems, (Ph.D. dissertation), http://www.umass.edu/expecon/

Fujikawa, T., 2007. Perfect Bayesian Vs. imperfect Bayesian in small decision making problems. Behaviormetrika, 34: 27-44. ISSN: 1349-6964

Fujikawa, T., 2009. On the Relative importance of the hot stove effect and the tendency to rely on small samples. Judgment Decision Mak., 4: 429-435. http://journal.sjdm.org/9521/jdm9521.pdf

Fujikawa, T., 2005. An experimental study of petty corrupt behaviour in small decision making problems. Am. J. Applied Sci., 14-18. DOI: 10.3844/ajassp.200514.18
Fujikawa, T. and S.H. Oda, 2005. A laboratory study of bayesian updating in small feedback-based decision problems. Am. J. Applied Sci., 2: 11291133. DOI: 10.3844/ajassp. 2005.1129.1133

Giambra, L.M., C.J. Camp and A. Grodsky, 1992. Curiosity and stimulation seeking across the adult life span: Cross-sectional and 6-8 year longitudinal findings. Psychol. Aging, 7: 150-157.

Greenlund, K.J., C.C. Johnson, L.S. Webber and G.S. Berenson, 1997. Cigarette smoking attitudes and first use among third- through sixth-grade students: The Bogalusa heart study. Am. J. Public Health, 87: 1345-1348. http://www.ncbi.nlm.nih.gov/pubmed/9279273

Hertwig, R. and A. Ortmann, 2001. Experimental practices in economics: A methodological challenge for psychologists. Behav. Brain Sci., 24: 383-403. http://www.ncbi.nlm.nih.gov/pubmed/11682798

Hertwig, R. and A. Ortmann, 2008. Deception in experiments: Revisiting the arguments in its defense. Ethics Behav., 18: 59-92. DOI: 10.1080/10508420701712990

Hunt, J.M., 1963. Motivation Inherent in Information Processing and Action. In: Motivation and Social Interaction, Harvey, O.J. (Ed.). Ronald Press, New York, pp: 35-94.

Jamal, K. and S. Sunder, 1991. Money Vs gaming: Effects of salient monetary payments in double oral auctions. Org. Behav. Hum. Decision Processes, 49: 151-166. DOI: 10.1016/0749-5978(91)90046-V

Knutson, B. and R. Peterson, 2005. Neurally reconstructing expected utility. Games Econ. Behav., 52: 305-315. DOI: 10.1016/j.geb.2005.01.002

Krueger, J. and R.W. Clement, 1994. The truly false consensus effect: An ineradicable and egocentric bias in social perception. J. Personality Soc. Psychol., 67: 596-610. http://www.ncbi.nlm.nih.gov/pubmed/7965607

Litman, J.A. and C.D. Spielberger, 2003. Measuring epistemic curiosity and its diversive and specific components. J. Personality Assess., 80: 75-86. http://www.citeulike.org/user/jbdayez/article/1623427

Loewenstein, G., 1994. The psychology of curiosity: A review and reinterpretation. Psychol. Bull., 116: 75-98.

Loewy, E.H., 1998. Curiosity, imagination, compassion, science and ethics: Do curiosity and imagination serve a central function. Health Care Anal., 6: 288-294. DOI: 10.1007/BF02678364

Lowry, N. and D.W. Johnson, 1981. Effects of controversy on epistemic curiosity, achievement and attitudes. J. Soc. Psychol., 115: 31-43. 
Lucas, K. and B. Lloyd, 1999. Starting smoking: Girls' explanations of the influence of peers. J. Adolescence, 22: 647-655. DOI: 10.1006/JADO.1999.0260

Madu, S.N. and M.P. Matla, 2003. Illicit drug use, cigarette smoking and alcohol drinking behavior among a sample of high school adolescents in the Pietersburg area of the northern province, South Africa. J. Adolescence, 26: 121-136. ISSN: 0140-1971

Moon, H.R., 2004. Maximum score estimation of a nonstationary binary choice model. J. Econ., 122: $385-403$. http://ideas.repec.org/a/eee/econom/v122y2004i2p 385-403.html

Mukerji, S., 1998. Ambiguity aversion and the incompleteness of contractual form. Am. Econ. Rev., 88: 1207-1231.

National Institutes of Health, 1976. Teenage Smoking, National Patterns of Cigarette Smoking, Ages 12 through 18, in 1972 and 1974. 1st Edn., National Institutes of Health, DHEW, pp: 15.

Offerman, T., J. Sonnemans and A. Schram, 1996. Value orientations, expectations and voluntary contributions in public goods. Econ. J., 106: 817-845. http://ideas.repec.org/a/ecj/econjl/v106y1996i437p81 7-45.html

Olson, K.R. and C.J. Camp, 1984. Factor analysis of curiosity measures in adults. Psychol. Reports, 54: 71-74.

Piaget, J., 1950. Psychology of Intelligence. 2nd Edn., Littlefield, Adams, New York, pp: 216.

Rapoport, A., 1988. Provision of step-level public goods: Effects of inequality in resources. J. Personality Soc. Psychol., 54: 432-440.

Reio, T.G., Jr., 2003. Curiosity. In: Human Ecology: An Encyclopedia of Children, Families, Communities and Environments, Miller, J.M., R.M. Lerner, L.B. Schiamberg and P.M. Anderson (Eds.). ABC-Clio, Santa Barbara, pp: 159-161.

Reio, T.G., Jr. and J.M. Petrosko, 2006. The measurement and conceptualization of curiosity. J. Genet. $\quad$ Psychol., 167: 117-135. DOI: 10.3200/GNTP.167.2.117-135

Reio, T.G., Jr. and A.K. Wiswell, 2000. Field investigation of the relationship among adult curiosity, workplace learning and job performance. Hum. Resour. Dev. Q., 11: 5-30. DOI: $10.1002 / 1532-1096(200021)$
Shafir, E. and A. Tversky, 1992. Thinking through uncertainty: Nonconsequential reasoning and choice. Cognitive Psychol., 24: 449-474. http://www.ncbi.nlm.nih.gov/pubmed/1473331

Sherman, S.J., C.C. Presson and L. Chassin, 1984. Mechanisms underlying the false consensus effect: The special role of threats to the self. Personality Soc. Psychol. Bull., 10: 127-138. http://psp.sagepub.com/content/10/1/127.short

Smith, V.L., 1991. Rational choice: The contrast between economics and psychology. J. Polit. Econ., $\quad$ 99: 877-897. http://ideas.repec.org/a/ucp/jpolec/v99y1991i4p877 $-97 . h \mathrm{tml}$

Smith, V.L. and J.M. Walker, 1993. Rewards, experience and decision costs in first price auctions. Econ. Inq., 31: 237-244.

Sonnemans, J., 1998. Strategies of search. J. Econ. Behav. Org., 35: 309-332.

Spielberger, C.D. and L.M. Starr, 1994. Curiosity and Exploratory Behavior. In: Motivation: Theory and Research, O'Neil, H.F., Jr. and M. Drillings (Eds.). Erlbaum, Hillsdale, NJ, pp: 221-243.

Stockman III, J.A., 2006. Clinical facts and curios. Current Problems in Pediatric and Adolescent Health Care, 36: 68-72.

Suleiman, R. and A. Rapoport, 1992. Provision of steplevel public goods with continuous contribution. J.

Behav. Decision Mak., 5: 133-153. DOI: 10.1002/bdm.3960050205

Teraji, S., 2003. Herd behavior and the quality of opinions. J. Socio-Econ., 32: 661-673. http://ideas.repec.org/a/eee/soceco/v32y2003i6p66 1-673.html

Thaler, R.H., A. Tversky, D. Kahneman and A. Schwartz, 1997. The effect of myopia and loss aversion on risk taking: An experimental test. Q. J. Econ., 112: 647-661. http://ideas.repec.org/a/tpr/qjecon/v112y1997i2p64 7-61.html

Tuakli, N., M.A. Smith and C. Heaton, 1990. Smoking in adolescence: Methods for health education and smoking cessation, a MIRNET study. J. Family Practice, 31: 369-374. http://www.ncbi.nlm.nih.gov/pubmed/2212967

Zak, P.J., 2004. Neuroeconomics. Philos. Trans. Royal Soc., 359: 1737-1748. 